\title{
Çift Merdaneli Sürekli Döküm Tekniği ile Üretilmiş AZ ve AM Serisi Magnezyum Alaşımlarının Korozyon Davranışlarının Karşılaştırılması
}

\author{
Fehmi KALAYCI ${ }^{1} \mathscr{\&}$, Emin ZUBAROĞLU ${ }^{2}$ \\ ${ }^{1}$ Erciş MYO, Yüzüncü Yıl Üniversitesi, Van, Türkiye \\ ${ }^{2}$ Samandağı Meslek ve Teknik Anadolu Lisesi, Hatay, Türkiye \\ 凹: fehmikalayci@gmail.com.tr
}

\section{ÖZ}

Magnezyum alaşımlarının diğer metalik yapısal malzemelerin tümüne göre yoğunluğunun düşük ve spesifik mukavemetinin yüksek oluşu başta otomotiv, uçak ve uzay olmak üzere bir çok endüstri alanının yoğun ilgisini üzerine çekmektedir. Günümüzde, magnezyum esaslı sac levhaların üretim süreçleri ve mekanik özellikleri üzerine birçok çalı̧̧ma yapılmış olmasına karşın bu malzemelerin korozyon davranışı üzerine yapılan çalışmalar halen devam etmektedir. Ayrıca Mg ve alaşımlarının korozyon hızı uygulanacak ısıl işlemler ile de değişebilmektedir.

Yeni alaşım bileşimleri geliştirmek ve farklı şekillendirme yöntemlerinin potansiyelini ortaya koymak amacıyla yoğurma alaşımları üzerinde çok kapsamlı araştırmalar sürmektedir. Bu çalışmada, çift merdaneli sürekli döküm yöntemi ile üretilmiş $\mathrm{AZ}$ ve $\mathrm{AM}$ serisi alaşımlı levhaların korozyon davranışları potansiyodinamik polarizasyon (PDS) teknikleri kullanılarak \%3,5 $\mathrm{NaCl}$ çözeltisi içerisinde araştııılmıştır.

Anahtar Kelimeler: AZ ve AM, Korozyon, Magnezyum.

\section{Comparison of Corrosion Behaviours of AZ and AM Serıes Magnesium Alloys Produced by Double Large Contınuous Castıng Technıque}

\begin{abstract}
Magnesium alloys have low density and high specific strength compared to other metallic structural materials, and they are attracted to the intense interest of many industries, especially automotive, aircraft and space. Today, many studies have been carried out on the production processes and mechanical properties of magnesium-based sheet metal, but studies on the corrosion behaviour of these materials are still in progress. In addition, the corrosion rate of $\mathrm{Mg}$ and its alloys can be changed by heat treatment. Extensive research is underway on kneading alloys to develop new alloy compositions and to demonstrate the potential of different forming methods. In this study, corrosion behaviour of $\mathrm{AZ}$ and $\mathrm{AM}$ series alloy plates produced by double cast continuous casting method was investigated in $3,5 \% \mathrm{NaCl}$ solution using potentiodynamic polarization (PDS) techniques
\end{abstract}

Keywords: AZ and AM, Corrosion, Magnesium.

\section{GiRiş}

Magnezyuma XXI. yüzyılın en popüler metalik malzemesi gözü ile bakılmaktadır. Sahip olduğu $1.74 \mathrm{gr} / \mathrm{cm}^{3}$ yoğunluğu ile alüminyumdan $\% 36$, çelikten $\% 78$ daha hafif olan magnezyum alaşımları, yapısal metaller arasında en hafif olanıdır. Pek çok magnezyum alaşımı ise yapısal metaller içerisinde oldukça yüksek spesifik mukavemet oranına sahiptir [1-4]. Mg 'hegzagonal' bir kafes yapısına sahiptir. Sahip olduğu atom yarıçap1 da çok fazla sayıda elementle katı çözünürlüğe müsaade eder.

Magnezyum en hafif yapisal metal olmasi nedeniyle ağırlık tasarrufu istenilen, otomotiv, uzay-uçak, elektronik, askeri vb. alanlarda giderek artan bir şekilde kullanıma girmektedir. Bunun yanı sıra, iyi dökülebilirlik özellikleri, yüksek sönümleme kapasitesi, elektromanyetik etkenlere karşı iyi bir kalkan olması, 1sıyı çok iyi dağıtması magnezyum alaşımlarını özellikle otomotiv endüstrisi için aday malzemeler arasında en üst sıralarda tutmaktadır [2, 5-7].

B-36 bombardıman uçağının ağırlığ toplam 8,6 tondur. Yaklaşık 3,4 ton $\mathrm{Mg}$ alaşımlarından oluşmaktadır. $\mathrm{Mg}$ alaşımı yerine $\mathrm{Al}$ alaşımı kullanılmış olsaydı 4,5 tonluk fazla bir ağırlık oluşturacaktı [8]. Magnezyum alaşımlarının önemi, yüksek mukavemet / ağırlık oranı, yüksek boyutsal kararlılık, iyi işleme ve geri dönüştürülebilme özelliği nedeniyle çeşitli endüstrilerde önemli ölçüde artmıştır [9]. 
Günümüzde teknolojinin ilerlemesine paralel olarak malzemelerden istenen özellikler de değişmektedir. Buna bağlı olarak malzemeler çeşitli işlemlerden geçirilerek korozyon direnci, dayanımı ve ortama uyum gibi özellikleri olumlu yönde değiştirilebilmektedir. Saf halde mekanik özellikleri oldukça düşük olmasına karşın özellikle alüminyum (Al), çinko ( $\mathrm{Zn})$ ve manganla (Mn) alaşımlandığında, bu özellikler belirginlik kazanmaktadır [10-12]. En yaygın alaşımlar, mekanik özellikleri iyi tespit edilen Al-Mn (AM50, AM60 gibi) alaşımları ile Al-Zn (AZ31, AZ91 gibi) alaşımlarıdır. Yüksek sıcaklıktaki iyi sürünme direncine sahip olan diğer $\mathrm{Mg}$ alaşımları ise nadir elementlerden oluşturulmaktadır [13].

Magnezyum, özellikle $\mathrm{Al}, \mathrm{Zn}$ ve Mn başta olmak üzere, toprak alkali metaller ve eser miktarlardaki $\mathrm{Si}, \mathrm{Y}, \mathrm{Ca}, \mathrm{Sr}, \mathrm{Ba}, \mathrm{Sb}, \mathrm{Sn}, \mathrm{Pb}$ ve Bi gibi elementlerle alaşımlandırma yapılarak, mekanik özellikleri artırılmakta ve ortaya koyduğu performansla kullanım sahası giderek artmaktadır. $\mathrm{Mg}-\mathrm{Al}-\mathrm{Zn}$ (AZ91) alaşımları, çoğunlukla otomobil parçalarının dökümü için kullanılır ve bu alaşımın dökülebilirlik kabiliyeti oldukça iyidir [6]. Bazı çalışmalarda özellikle magnezyum ve alaşımlarına çeşitli 1sıl işlemler uygulayarak korozyon duyarlılığını azaltmaya odaklanılmıştır [14].

Günümüzde, magnezyum esaslı sac levhaların üretim süreçleri ve mekanik özellikleri üzerine birçok çalışma yapılmış olmasına karşın bu malzemelerin korozyon davranışı üzerine yapılan çalışmalar halen devam etmektedir. Ayrıca, Mg ve alaşımlarının korozyon hızı uygulanacak 1sıl işlemler ile de değişebilmektedir. . Yeni alaşımlar ve farklı şekillendirme yöntemlerinin potansiyelini ortaya koymak amacıyla yoğurma alaşımları üzerinde detaylı çalışmalar devam etmektedir. Çevreyi korumak amacıyla Avrupa Birliğinin yasal zorunluluklar getirmesinden dolayı, araçların ağırlığının azaltılma gereksinimi, magnezyuma alaşımlarına olan ilginin artmasına neden olmuştur. $\mathrm{Bu}$ konuda yeni alaşım geliştirme ve tasarım iyileştirme süreçleri başlatılmıştır [15].

Magnezyum zararlı toksitler çıkarmaz ve bilinen bütün yöntemlerle şekillendirilebilir bir elementtir [16]. Magnezyum alaşımlarının çeşitli sektörlerde giderek artan öneme sahip olmasının diğer nedenleri ise yüksek boyutsal kararlılığı ve tamamen geri dönüşebilir olmasıdır. Ayrıca, enerji ve hammadde kaynaklarının korunması, geri dönüşümüne olanak sağlanması kullanılacak malzemenin seçiminde önemli etkenlerden birisi olmaktadır [17].

Magnezyum alaşımları bilhassa metalik impuriteler ya da klor iyonlarınca zengin ortamlarda korozyon açısından oldukça savunmasızdırlar. Fakat oluşturdukları koruyucu oksit tabaka nedeniyle genellikle korozif ortamda orta karbonlu çelikten daha çok atmosferik korozyona karşı dayanıklıdırlar [10, 18]. AZ91 gibi döküm alaşımlarının korozyon direnci bazı Al alaşımları ve çelik ile karşılaştırıldığında çok daha iyidir. Genel olarak, $\mathrm{Mg}$ alaşımlarının korozyon hızı alüminyum (Al) ile orta karbonlu çelik arasında yer alır. Hatta bazı durumlarda Al'dan daha iyidir.

Araçların kaput, bagaj kapağı ve kapı gibi bükülmezlik gerektiren geniş dış parçalarında magnezyum alaşımları çeliğe oranla \%50, alüminyuma oranla $\% 20$ ağırlı kazanc1 oluşturmaktadır. Genelde mekanik özelliklere odaklanarak eklenen bu alaşımlandırma elementlerinin alaşımın korozyon davranışını nasıl etkilediği konusunda ise çalışmalar devam etmektedir. $\mathrm{Bu}$ konudaki eksiklik bu alaşımların mühendislik uygulamalarında kullanımını oldukça sinırlamaktadır.

Plaka, levha, folyo, çubuk, boru ve profil ve dövme mamullerin eldesi için kullanılan deformasyon kabiliyeti nispeten yüksek alaşımlar, magnezyum yoğurma alaşımlarıdır. Yoğurma alaşımları döküm alaşımlarına göre segregasyon içermemeleri, ince tane yapıları nedeniyle daha iyi mekanik ve korozyon direnci özellikleri sergilemektedir[19].

Ergitme + külçe + homojenleştirme isıl işlemi + haddeleme + 1sitma + sicak haddeleme +11 k haddeleme + soğuk haddeleme + yaşlandırma tavı gibi geleneksel külçe haddesi ile levha üretimi oldukça fazla işlemlerden oluşmaktadır. Bu nedenle geleneksel döküm tekniğinde enerji ve zaman kaybı ihmal edilemeyecek düzeyde yüksektir. Ayrıca geleneksel külçe haddesi ile levha üretimi ekonomik bir yöntem olmadığı için magnezyumun üstün özelliklerine rağmen $\mathrm{Mg}$-levha halen geniş çaplı bir endüstriyel tüketime ve üretime sahip değildir. Haddeleme kademelerini minimuma indirecek ve ekonomiklik sağlayacak yegâne yöntem çift merdaneli direkt levha dökümüdür [20]. Çift merdaneli döküm tekniğinde döküm tekniğinde levha bu kadar işlemden geçmeden direkt olarak elde edildiği için külçe haddelemesine dayanan konvansiyonel levha üretimine nazaran çok daha ucuz olarak üretilmektedir [1]. Aynı zamanda çift merdaneli döküm yönteminde malzemenin mikroyapısı iyileşmekle birlikte deformasyona izin veren malzemede üretilebilmektedir [20].

Yapılan çalışmalar, özellikle magnezyum ve alaşımlarına çeşitli 1 sıl işlemler uygulayarak korozyon duyarlılığını azaltmaya odaklanmıştır [21]. Magnezyum alaşımlarının üretim süreçleri ve mekanik özellikleri üzerine birçok çalışma yapılmış olmasına karşın bu malzemelerin korozyon davranışı üzerine yapılan çalışmalar halen devam etmektedir.

Birçok magnezyum alaşımının düşük korozyon direncinin başlıca iki temel sebebi vardır. Birincisi, iç galvanik korozyon, buna ikincil fazlar veya impüritelerin (kirlilik) sebep olduğu düşünülmektedir. $\mathrm{Mg}$ alaşımları içerdikleri kirleticiler $(\mathrm{Fe}, \mathrm{Ni}$, ve $\mathrm{Cu}$ ), nedeniyle nemli ve anodik magnezyum matris ile mikro hücreler 
meydana getirirler. İkinci temel sebep ise; magnezyum üzerindeki yarı pasif hidroksit filmin, alüminyum ve paslanmaz çelik gibi metaller üzerinde oluşan pasif filmlerden çok daha az stabil olmasıdır. Oluşan bu film tabaka magnezyum ve

alaşımlarını çukurcuk korozyonuna karşı hassas duruma getirmektedir. Bu durumda, magnezyum ve alaşımlarının korozyonu genellikle lokalize korozyon şeklinde oluşmaktadır. Bu alaşımların korozyon morfolojileri ise alaşım kompozisyonu ve çevre şartlarıyla yakından ilişkilidir [22].

\section{MATERYAL ve YÖNTEM}

Mg alaşımları; sırası ile iki harf, iki haneli rakamlar şeklinde kodlanarak işaretlenmektedir[23]. Harfler ana alaşım elementlerini göstermekte rakamlar ise bu elementlerin yüzdelerini belirtmektedir. Yüzdeler en yakın tam sayıya yuvarlanarak yazılmaktadır.

Homojenleştirme 1 ssl işlemi yapı içerisindeki mikrosegregasyon oranını azaltmak, düşük ergime noktalı ötektik fazları uzaklaştırmak, katılaşma

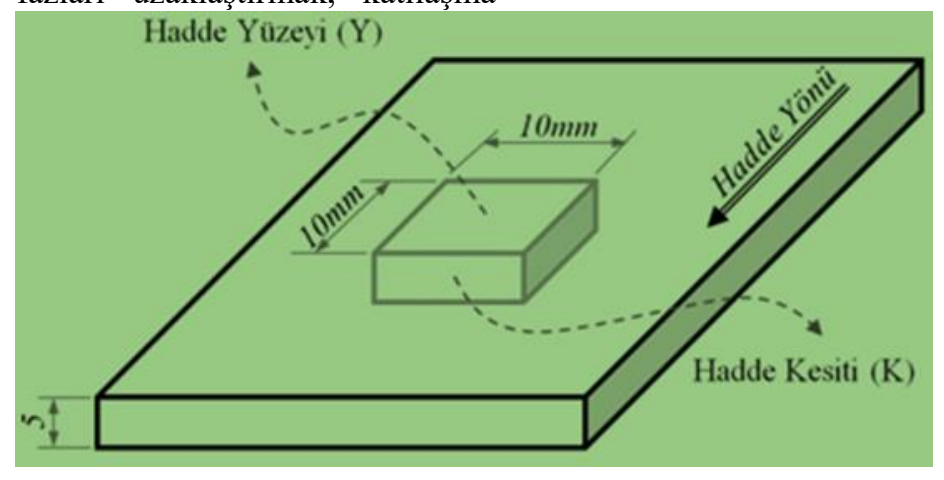

Şekil 1. Haddelenmiş Mg alaşımı levhalarından numunelerin çıkarılışı.

Çalışma elektrotlarını aynı yüzey pürüzlülük değerlerine ulaştırmak için sırasıyla 180, 240, 400, $600,800,1000$ ve 1200 numara silisyum karbür bazlı zımpara kâğıtları kullanılarak taşlanmıştır. Ardından numune yüzeyleri 6,3 ve $1 \mu$ boyutundaki elmas süspansiyonlarla parlatılmıştır. Her bir zımparalama ve parlatma kademesinden sonra bir önceki zımparalama/parlatma kademesinde numune yüzeyinde kalan aşındırıcı parçacıkları uzaklaştırmak için numuneler 5'er dakika süreyle etil alkol içerisinde ultrasonik olarak temizlenmiştir.

Deneyler \%3,5 $\mathrm{NaCl}$ çözeltisi kullanılarak 500 ml.'lik korozyon hücresi içerisinde gerçekleştirilmiştir. Deneyler GAMRY (USA) firmasının ürettiği PCI14/750 test cihazı kullanılarak \%3,5 $\mathrm{NaCl}$ çözeltileri içerisinde yapılmıştır. Tüm ölçümler üç elektrot tekniğine göre yapılmıştır. Deneylerde, referans elektrot (RE4) olarak doygun gümüş/gümüş klorür elektrot $(\mathrm{Ag} / \mathrm{AgCl})$, karşıt elektrot (CE5) olarak platin (Pt) esnasında çözülmüş elementlerin kontrollü bir şekilde çökelmelerini sağlamak için yapılmıştır. Homojenizasyon işlemi başlıca alaşım elementlerinin zengin olarak bulundukları tane sınırlarından tane içlerine doğru difüzyon yardımıyla geçmesini sağlar. $\mathrm{Bu}$ işlemin tamamlanması için belli bir süreye ihtiyaç vardır ayrıca artan sıcaklık ile difüzyon oranı artmaktadır. $\mathrm{Bu}$ çalışmada, haddeleme yöntemi ile üretilmiş $\mathrm{Mg}$ alaşım örnekleri laboratuar firınında $400^{\circ} \mathrm{C}$ 'de 6 saat süreyle tavlanarak homojenize edilmiştir. Ardından örnekler firından alınıp havada soğutulmuştur. $\mathrm{Bu}$ tavlama işlemi için kullanılan parametreler homojenleştirme işlemi için sunulan endüstriyel skalalar temel alınarak uygulanmıştır. Üretimi ve 1sıl işlemi gerçekleştirilen magnezyum alaşımı levhalardan, $1 \times 1 \mathrm{~cm}^{2}$ alanlı parçalar kesilip (Şekil 1), bir yüzeyi elektron geçişini sağlayabilmesi için bakır bir tel ile sıkı geçme olacak şekilde birleştirilmiştir. 
bakır ve kobalt gibi elementler oldukça zararlı etkiye sahiptirler. Magnezyumun korozyon direnci üzerine en az zararlı etkiye sahip alaşım elementlerinin ise $\mathrm{Al}, \mathrm{Mn}, \mathrm{Na}, \mathrm{Si}, \mathrm{Pb}$ olduğu yine dikkati çeken diğer bir noktadır. Bu çalışmada $\mathrm{Mg}$ levhaların alaşımlanmasında korozyon bakımından en az etkili olan bu alaşımlardan $\mathrm{Al}$ ve $\mathrm{Mn}$ tercih edilmiştir.

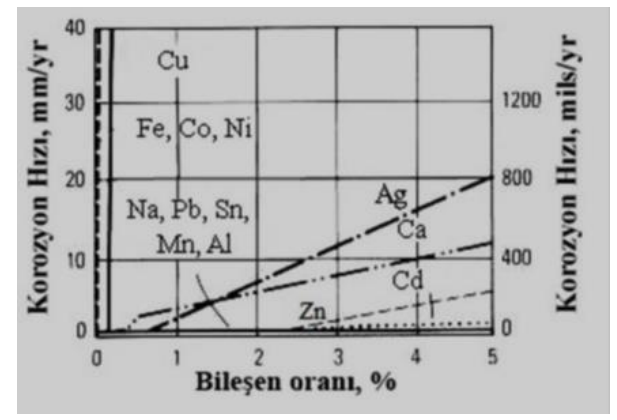

Şekil2. \%3 $\mathrm{NaCl}$ içeren çözelti içerisinde Mg'un korozyon hızı üzerine alaşım elementlerinin etkisi [24].

Magnezyum alaşımların korozyon dayanımlarının arttırılması konusundaki önemli gelişmeler 1980’li y1llarda meydana gelmiştir. Son yıllarda ise, AZ91HP ve WE54 (Mg-5.2Y-3.5Re-0.5Zr) gibi yüksek korozyon dayanımına ve deformasyon kabiliyetine sahip magnezyum alaşımları geliştirilmiştir ve bu şekilde otomobil parçalarındaki korozyon problemi büyük ölçüde ortadan kaldırılmaya çalışılmıştır [25]. Otomotiv endüstrisinde kullanılan önemli magnezyum alaşım grupları alüminyum, çinko ve toprak alkali metalleri içeren alaşımlardır. Magnezyumalüminyum-çinko alaşımı AZ91 (\%9Al, \%1Zn), en yaygın magnezyum döküm alaşımıdır ve konvansiyonel alüminyum alaşımlarına yakın korozyon dayanımına sahiptir [19]. AZ91 alaşımı özellikle otomotiv, bilgisayar ve uçak gibi endüstri kollarında geniş uygulama alanları bulmaktadır. Yüksek saflıktaki Mg alaşımları sergiledikleri iyi korozyon dirençleri nedeniyle nükleer endüstri alanlarında kullanılmaktadırlar.

Magnezyumun alaşımlanmasında kullanılan başlıca elementler $\mathrm{Al}, \mathrm{Zn}, \mathrm{Mn}$ ve benzer gruplardır. Fe, Co, $\mathrm{Ni}$ ve $\mathrm{Cu}$ elementleri ise magnezyum alaşımlarının korozyonu için zararlıdır. Tüm bu alaşım elemanlarının eşik sınır değerleri Mg'nin lokalize korozyonu üzerinde oldukça önemli etkilere sahiptir. Bu alaşım elemanlarının oluşturduğu çoğu katodik karakterli impuriteler yada çökeltiler mikro, sub-mikro lokal pillerin (korozyon hücrelerinin) oluşumunda görev alırlar. Özetle yapılan çalışmalar $\mathrm{Na}, \mathrm{Si}, \mathrm{Pb}, \mathrm{Sn}, \mathrm{Mn}$ ve Al alaşımları için \%5'in altında bulunmaları halinde Mg'nin korozyon davranışı üzerinde ihmal edilebilir bir etki bıraktığını, ancak, $\mathrm{Fe}, \mathrm{Ni}, \mathrm{Co}$ ve $\mathrm{Cu}$ 'nun ise çok düşük konsantrasyonlarda olsalar bile oldukça zararlı etkiler ortaya çıkardıklarını göstermektedir
[28]. Örneğin \%5'lik NaCl çözeltisindeki AZ91, AZ61 ve AZ31'in korozyon hızları Al içeriğinin azalmasıyla artmaktadir [27].

Mikro yapıda segregasyon kompozisyonu korozyon davranışları üzerinde önemli etkiye sahiptir. Örneğin, Mn içeren AM50 ve AM20 magnezyum alaşımlarının korozyon testleri, çukurcukların düşük $\mathrm{Al}$ içeren alanlarda başladığını göstermektedir. $\mathrm{Bu}$ bölgelerinden başlayan çukurcuk korozyon ilerlemesi genellikle yüksek Al segregasyonunun bulunduğu alanlara ulaşınca durur [29].

Mn magnezyum alaşımlarının korozyon direncini iyileştirebilir; fakat bu durum her zaman geçerli değildir. Magnezyum alaşımlarının korozyon hızı alaşımın Fe oranı ve Fe/Mn oranına bağlıdır. Daha düşük Al/Mn oranlı ve ikili Al-Mn fazı daha yüksek alaşımlar katodik potansiyele sahiptir. Bununla birlikte $\mathrm{Mg}$-Al alaşımları içine Al-Mn ve Al-Mn-Fe intermetalik fazını oluşturmak için Mn eklendiği zaman korozyon hızı artar[29].

Yapılan çalışmalar, $\mathrm{Mg}$ alaşımı içerisindeki Al oranının \%1'den \%8'e artırlliyorken gerilmeli korozyon kırılma duyarlılığının arttığını göstermektedir [12]. Ayrıca, artan Zn içeriğinin de gerilmeli korozyon kırılma duyarlılığını arttırdığ bilinmektedir.

\section{BULGULAR VE TARTIŞMA}

Şekil 3 ve 4 incelendiğinde $\% 3,5 \mathrm{NaCl}$ çözeltisinde homojenizasyon 1sıl işlemi görmüş numunelerin korozyon direncinin isıl işlem görmemiş numunelere göre daha iyi olduğu görülmektedir. \% $3.5 \mathrm{NaCl}$ çözeltisinde homojenizasyon 1sıl işlemi görmüş numunelerin korozyon potansiyelleri (Ecorr: -1362 / -1249 mV), homojenizasyon 1s1l işlemi görmemiş numunelerin polarizasyon akım değerine göre (Ecorr: -1409 / -1338 mV) daha düşüktür.

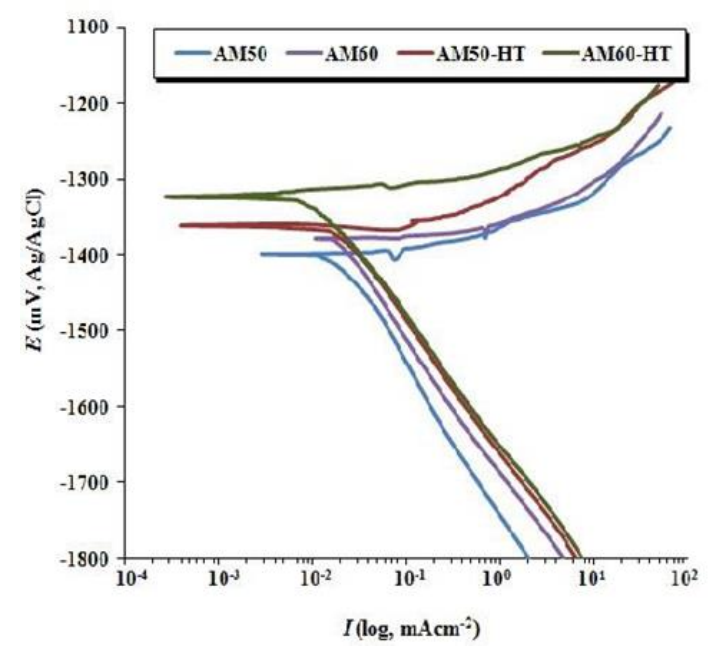

Şekil3. Homojenleştirme 1s1l işlemi görmüş ve görmemiş AM50 ve AM60 magnezyum alaşımı levhaların\%3,5'lik $\mathrm{NaCl}$ çözeltisi içerisindeki karşılaştırılmalı PDS eğrileri 
Tablo 2. Polarizasyon eğrilerinden elde edilen korozyon parametreleri

\begin{tabular}{cccccc}
\hline Alaşım & $\begin{array}{c}\text { Eocp } \\
(\mathrm{mV})\end{array}$ & $\begin{array}{c}\text { Ecorr } \\
(\mathrm{mV})\end{array}$ & $\begin{array}{c}\text { I cor } \\
(\mu \mathrm{A} / \mathrm{cm} 2)\end{array}$ & $\begin{array}{c}\beta c \\
(\mathrm{mV} / \text { dec. })\end{array}$ & $\begin{array}{c}\beta A \\
(\mathrm{mV} / \text { dec. })\end{array}$ \\
\hline AZ31 & -1543 & -1409 & 40,16 & $-189,70$ & 61,28 \\
AZ61 & -1516 & -1381 & 33,02 & $-195,40$ & 44,76 \\
AZ91 & -1501 & -1338 & 20,76 & $-213,10$ & 31,55 \\
AZ31-HT & -1539 & -1335 & 45,94 & $-183,30$ & 53,43 \\
AZ61-HT & -1509 & -1310 & 19,36 & $-180,80$ & 31,46 \\
AZ91-HT & -1495 & -1249 & 4,02 & $-179,40$ & 7,67 \\
AM50 & -1518 & 1399 & 21,82 & $-199,8$ & 31,68 \\
AM60 & -1509 & 1379 & 17,83 & $-182,5$ & 9,84 \\
AM50-HT & -1544 & -1362 & 26,01 & $-180,3$ & 43,61 \\
AM60-HT & -1551 & -1323 & 11,42 & $-173,9$ & 21,76
\end{tabular}

Eocp; açık devre potansiyelini, Ecorr; korozyon potansiyelini, Epit; çukurcuk potansiyelini, Icorr; korozyon akım yoğunluğunu, $\beta \mathrm{A}$ ve $\beta \mathrm{C}$ ise sırası ile anodik ve katodik Tafel sabitlerini ifade etmektedirler.

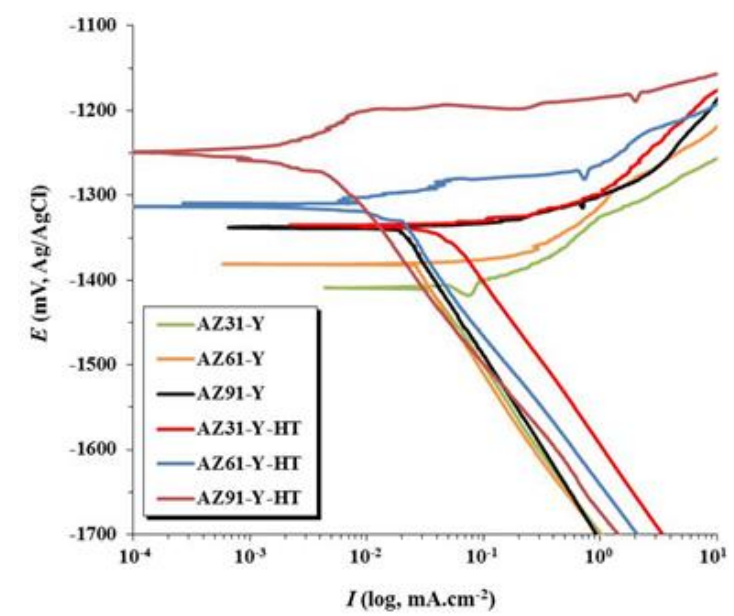

Şekil4. Homojenleştirme 1sıl işlemi görmüș ve görmemiş AZ31-61 ve $91 \mathrm{Mg}$ alaşımı levhaların \%3.5'lik $\mathrm{NaCl}$ çözeltisi içerisindeki karşılaştırılmalı PDS eğrileri.

Levhaların PDS eğrileri incelendiğinde tüm alaşımlardaki eğrilerin katodik bölgesinde potansiyel artıyorken akımın da lineer bir şekilde azaldığ1 görülmektedir. Bu durum tüm alaşımlarda aktivasyon kontrollü bir korozyon mekanizması olduğunu göstermektedir. $\mathrm{Bu}$ nedenle bazı durumlarda korozyon eğilimini belirlemede $\beta \mathrm{A}$ büyüklüklerini karşılaştırmak daha belirleyici olabilir.

Tablo 2'ye göre özellikle hadde yüzeylerinde, $\beta A$ değerlerinin $\mathrm{Al}$ alaşım miktarı arttıkça azalması bu numunelerde anodik aktivitelerin yavaşladığını göstermektedir.

Tablo 2' incelendiğinde ilk olarak, \%3,5 $\mathrm{NaCl}$ çözeltisinde HT (homojenleştirme tavı görmüş levhaları tanımlamak için 'HT' eki kullanılmıştır) işlemi uygulanmış levhaların isıl işlem uygulanmamış numunelere göre, AZ alaşımların AM alaşımlara göre korozyon dirençlerinin daha iyi olduğu dikkati çekmektedir.

Ayrıca, levhaların içerdiği Al alaşım miktarı arttıkça numunelerin genel korozyon özelliklerinin iyileştiği söylenebilir. Klasik düşünülürse, hem AZ hem de AM alaşımlarda Al içeriği arttıkça, Ecorr değerlerinin soylaştığı, Icorr korozyon akım yoğunluğu değerlerinin ise azaldığı bariz bir şekilde görülmektedir. AZ-HT işlemi uygulanmış levhaların AM-HT işlemi uygulanmış levhalara göre korozyon dirençlerinin daha iyi olduğu görülmektedir.

Ecorr potansiyel değerlerinin ve Icorr korozyon akım yoğunluğu değerlerinin AZ alaşımlarda AM alaşımlardan (HT işlemi uygulanmış veya uygulanmamış) daha iyi olduğu görülmektedir. Alaşımlar içerisinde en yüksek korozyon direnci bulunan numune hadde yüzeyinde $-1249 \mathrm{mV}$ 'luk korozyon potansiyeline sahip AZ91-HT alaşımıdır. Ayrıca Şekil 3-4 ve Tablo 2'yi incelendiğimizde alaşımların tümünün koruyuculuk bakımından saf Mg' ye göre oldukça iyi olduğu söylenebilir, çünkü literatürde saf $\mathrm{Mg}$ 'nin $\mathrm{NaCl}$ sulu çözelti içerisindeki korozyon potansiyeli yaklaşık $-1730 \mathrm{mV}$ civarında olduğu verilmiştir. Ayrıca, \%9 Al içeren bir $\mathrm{Mg}$ alaşımının klorürlü ortamlarda yüzeyi üzerinde oluşturduğu oksit filminin saf $\mathrm{Mg}$ üzerinde oluşan oksit filminden daha dirençli olduğunu litaratürde bildirmiştir.

Saf-Mg’ye, Al ve Mn'nin katılması, Mg'nin çözelti potansiyelini daha soy potansiyellere kaydırmaktadır ve bu alaşım elemanları içerisinde Al'un etkisi Mn ile karşılaştırılamayacak kadar çok daha büyüktür. Alaşım yüzeylerinde, $\mathrm{Al}$ ve $\mathrm{Mn}$ bulunan bölgelerde karma bir film oluşacaktır. 
Oluşan bu ince karma film elektriksel olarak $\mathrm{Al}_{2} \mathrm{O}_{3}$ oksit filminden daha iletkendir. Çünkü $\mathrm{Al}$, alaşım yüzeyinde n-tipi bir oksit filmi oluşturur ve bu oksit filminin elektriksel iletkenliği ortamın oksijen basıncı ile azalır [30]. Bu nedenle korozyon $\mathrm{Mg} / \mathrm{Al}$ arayüzeyinden daha ziyade $\mathrm{Mg} / \mathrm{Mn}$ ara yüzeylerinde devam eder (Şekil 5). Şekil 6'da alaşımlar üzerinde oluşan bu karma oksit film yapısı görülmektedir. Ayrıca, yapılan çalışmalar,
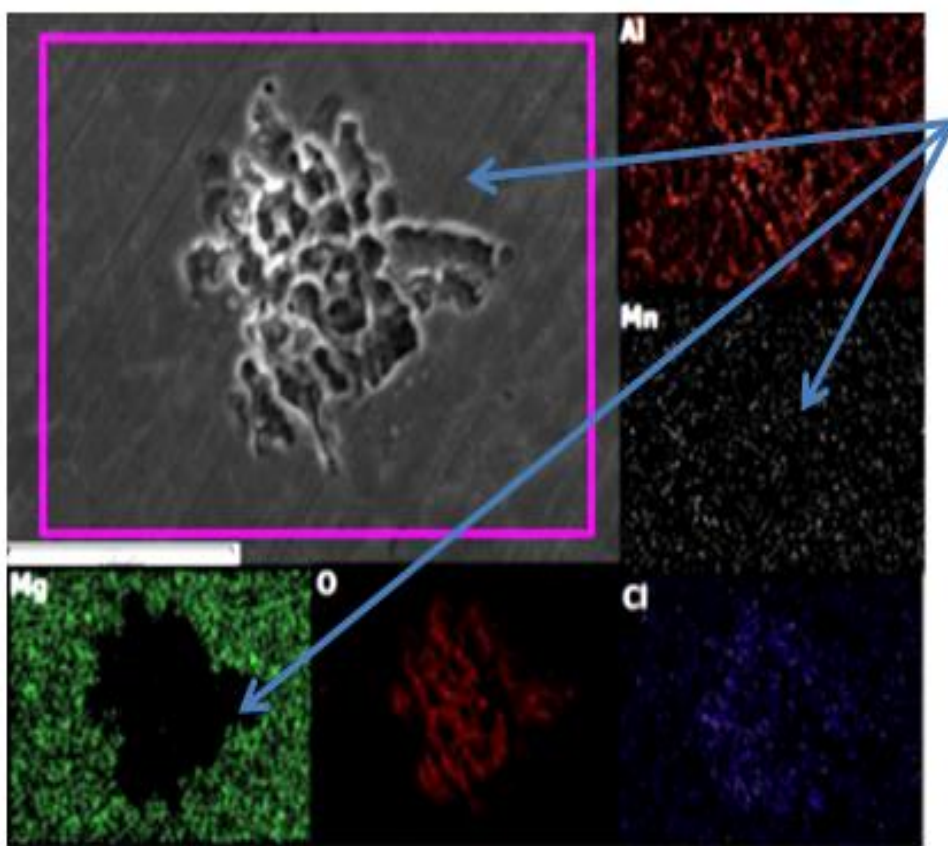

Mn içeren AM50 ve AM20 magnezyum alaşımlarının korozyon testlerinde, çukurcukların düşük $\mathrm{Al}$ içeren alanlarda başladığını göstermektedir. $\mathrm{Bu}$ çukurcuk bölgelerinden başlayan korozyon ilerlemesi genellikle yüksek Al segregasyonunun bulunduğu alanlara ulaşınca durmaktadır [26]. Şekil 5'de bu görüşü doğrulamaktadır.

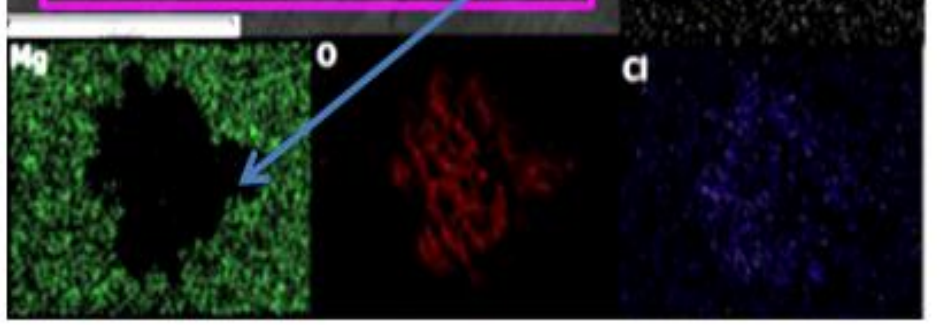

\section{Korozyon $\mathrm{Mg} / \mathrm{Al}$ \\ arayuzzeyinden daha \\ zyade $\mathrm{Mg} \mathrm{Mn}$ \\ arayüzeylerinde devam \\ eder}

Şekil5. Homojenleştirme Isıl İşlemi Görmemiş AM50 Magnezyum Alaşımı Levhanın Yüzey Oksit Filmi Üzerindeki Al, Mg, Mn, O ve Cl Elementlerinin Dağılımı. (Şekil, taramalı elektron mikroskobundan (SEM, JEOL JSM-6335F) elde edilmiştir)

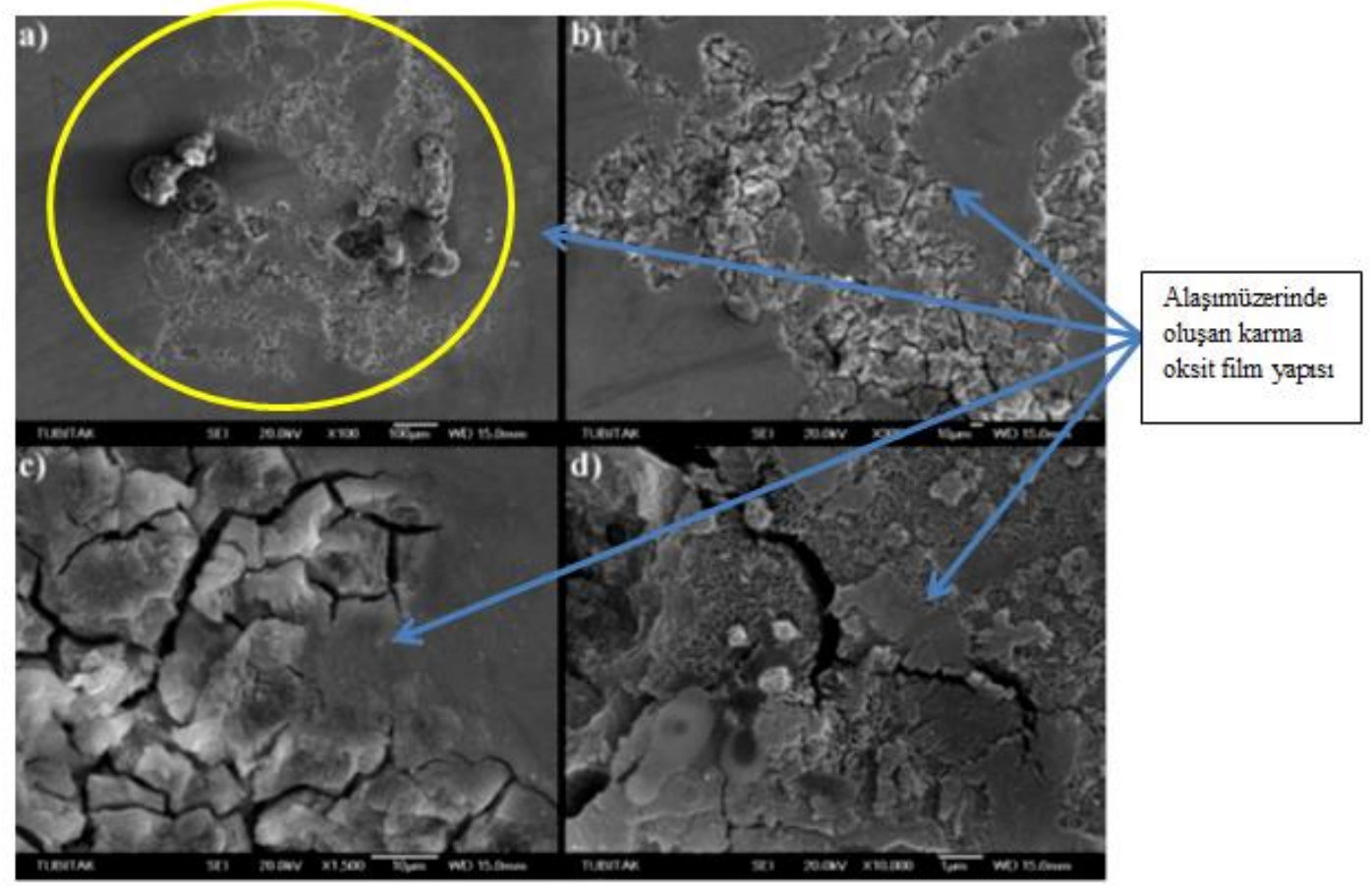

Şekil 6. AM60-HT Alaşımı Levhaların Değişik Büyütmelerdeki Korozyon Sonrası Yüzey Oksit Film Görüntüleri. a) x100 b) x300 c) x1500 d) x10000 büyültmeler. ( Şekil, taramalı elektron mikroskobundan (SEM, JEOL JSM$6335 \mathrm{~F}$ ) elde edilmiştir. 


\section{SONUC}

\%3,5 $\mathrm{NaCl}$ çözeltisi içerisinde korozyon davranışları incelenen alaşımların Açık Devre Potansiyel değerleri Tablo 2'den incelendiğinde 1sıl işlem öncesi numunelerin serbest potansiyellerinin daha soy değerlerde olduğu. Ancak, 1sıl işlem uygulanmış numunelerin, içinde bulundukları elektrolit ile daha kısa sürede kararlı hale ulaştığ HT numunelerin yüzeyinde daha sıkı ve dirençli ancak daha ince bir koruyucu oksit filmi oluştuğunu göstermektedir.

Ayrıca yapılan literatür karşılaştırmalarıyla AM ve AZ alaşımların tümünün koruyuculuk bakımından saf Mg'ye göre daha iyi olduğu görülmüştür.

Değişik anodik akımlara polarize edilen alaşımların SEM incelemelerinde çukurcukların düşük Al içeren alanlarda başladığı ve genellikle yüksek $\mathrm{Al}$ içeren bölgelere ulaşınca durduğu görülmüştür. (Şekil 5'de oklar ile gösterilmiştir.)

Literatür çalışmalarında, $\mathrm{Mg}$ alaşımlarının korozyonunun üniform korozyon şeklinde gelişiyorken ticari saflıktaki saf magnezyumun genlikle tanelerarası (transgranular) korozyona maruz kaldığı görülmüştür.

Literatür taramalarında özellikle magnezyum ve alaşımlarına çeşitli ısıl işlemler uygulanarak korozyon duyarlılığı azaltılmaya çalışılmıştır.

Yapılan incelemelerde, 1sıl işlem öncesinde alaşımlar içerisinde küçük oranlarda da olsa bir takım mikroporozite ve mikrosegregasyon izlerinin mevcut olduğu ancak; Homojenleştirme tavlaması sonrasında segregasyonların ve porozitelerin elimine edildiği görülmüştür.

Korozyon sonrası yapılan metalografik incelemelerde korozyonun tane sinırları boyunca ilerleyerek derinlemesine ve dar aralıklar şeklinde geliştiği görülmüştür. Isıl işlem sonrası korozyon morfolojisi tane sınırı korozyonu yerine çukurcuk korozyonuna dönüşmüştür.

Potansiyodinamik polarizasyon (PDS) teknikleri kullanılarak \%3,5 $\mathrm{NaCl}$ çözeltisi içerisinde yapılan çalışmaların sonucunda. Çift merdaneli sürekli döküm yöntemi ile üretilmiş AZ ve AM serisi alaşımlı levhaların korozyon davranışları incelendiğinde homojenizasyon 1sıl işlemi görmüş numunelerin korozyon potansiyelleri (Ecorr: -1362 / -1249 mV), homojenizasyon 1sıl işlemi görmemiş numunelerin korozyon potansiyel değerinden (Ecorr: -1409 / $1338 \mathrm{mV}$ ) daha düşük değerlerde olduğu görülmüştür.

\section{KAYNAKCA}

[1] Duygulu Ö., Yücel O., Kaya A. A. Magnezyum levha alaşımlarının üretimi ve geliştirilmesi, İTÜ Dergisi / D Mühendislik, 9, 4, 133-138, 2010.

[2] Watari H., Paisarn R., Haga T., Noda K., Davey K., Koga $\mathrm{N}$. Development of manufacturing process of wrought magnesium alloy sheets by twin roll casting, Journal of Achievements in Materials and Manufacturing Engineering, 20, 515-518, 2007.
[3] Doege E., Dröder K. Sheet metal forming of magnesium wought alloys - formability and process technology, Journal of Materials Processing Processing Technology, 115, 14-19, 2001

[4] Yoshihara S., Yamamoto H., Manabe K., Nishimura H. Formability enhancement in magnesium alloy deep drawing by local heating and cooling technique, Journal of Materials Processing Technology, 143-144, 612-615, 2003.

[5] Salman S. A., Ichino R., Okido M. A. Comparati and electrochemical study of AZ31 and AZ91 magnesium alloy, International Journal of Corrosion, 1-7, 2010.

[6] Elizer D., Aghion E., Froes F. H. Advanced performance materials, Magnesium Science Technology and Applications, 5, 201-202, 1998.

[7] Inoue H., Sugahara K., Yamamoto A., Tsubakino H. Corrosion rate of magnesium and its alloys in buffered chloride solutions, Corrosion Science, 44, 603-610, 2002.

[8] Öztürk F., Kaçar İ. Magnezyum alaşımları ve kullanım alanlarının incelenmesi, Niğde Üniversitesi Mühendislik Bilimleri Dergisi, 1, 12-20, 2012.

[9] Emley E. F. Principle of Magnesium Technology, Pergamon Press, London, UK, 1996.

[10] Song G., L., Atrens, A. Corrosion mechanisms of magnesium alloys, Advanced Engineering Materials, 1, 11-33, 1999.

[11] Chuvil'deev V. N., Nieh T. G., Gryaznov M. Y., Kopylov V. I., Sysoev A. N. Superplasticity and internal friction in microcrystalline AZ91 and ZK60 magnesium alloys processed by equal-channel angular pressing. Journal of Alloys and Compounds, 378, 253-257, 2004.

[12] Zeng R. C., Zhang J., Huang W. J., Dietzel W., Kainer K. U., Blawert C., Wei K. Review of studies on corrosion of magnesium alloys. Transactions of Nonferrous Metals Society of Chine, 16, 763-771, 2006.

[13] Zucchi F., Grassi V., Frignani A., Monticelli C., Trabanelli G. Electrochemical behaviour of a magnesium alloy containing rare earth elements. Journal of Applied Electrochemistry, 36, 195-204, 2006.

[14] Chang J. W., Guo X. W., Fu P. H., Peng L. M., Ding W. J. Relationship between heat treaatment and corrosion behaviour of $\mathrm{Mg} 3 \% \mathrm{Nd}-0,4 \% \mathrm{Zr} 64$ magnesium alloy. Transactions of Nonferrous Metals Society of Chine, 17, 1152-1157, 2007.

[15] Kacar İ., Öztürk F. Magnezyum alaşımlarının şekillendirilmesindeki son gelişmeler, TIMAK-Tasarım İmalat Analiz Kongresi, Balıkesir, 26-28, 2006.

[16] Song G., L., Andrej A., Matthew D. Influence of microstructure on the die cast AZ91D, Corrosion Science, 41, 249-273, 1999.

[17] Erçayan Y., İrizalp S. G., Saklakoğlu N. A380 alaşımında yarı-katı şekillendirmenin kompozit yapılara etkisinin incelenmesi, I. Ulusal Ege Kompozit Malzemeler Sempozyumu, İzmir, 2011.

[18] Gallaccio A., Cornet I. ASTM, 255, 1960.

[19] Duygulu Ö., Oktay G., Kaya A. A. Magnezyum alaşımlarının otomotiv sanayisinde kullanımı, Otomotiv Teknolojileri Kongresi, OTEKON2006, Bursa, 24-28, 2006.

[20] Ding P. D., Jiang B., Wang J., Pan F. S. Status and development of magnesium alloy thin strip casting, Materials Science Forum, 361- 364, 2007.

[21] Cheng Y. L., Q1n T. W., Wang H. M., Zhang Z. Comparison of corrosion behaviors of AZ31, AZ91, AM60 and ZK60 magnesium alloys. Trans. Nonferrous Met. Soc., China, 19, 517-524, 2009. 
[22] Polmear I. J. Light Alloys, Metallurgy of the Light Metals, 1989.

[23] Rudd A. L., Breslina C. B., Mansfeld F. The Corrosion protection afforded by rare earth conversion coatings applied to magnesium, Corrosion Science, 42, 275-288, 2000.

[24] Zhang Z., Development of magnesium-based alloys for elevated temperature applications, Doctor of These, Faculte Des Sciences Et De Genie Universite, QuebecCanada, 2-75, 2000.

[25] Bolstad J., Magnesium alloy development for intelligent magnesium designs, SinoMaG Seminar, Beijing-China, 8-14, 2000

[26] Froats A., Aune T. K., Hawke D., Unsworth W., Hillis J. Corrosion of magnesium and magnesium alloys, İn Metals Handbook, Metarials Park, 13, 740-754, 1987.

[27] Zeytin K., H. İnan, O. Teymur, B. Magnezyum alaşımlarının otomotiv endüstrisinde uygulaması ve geleceği, TÜBİTAK-MAM, 1999.

[28] Danielson M. J. Corrosion technology, 22. environmental effects on engineering materials magnesium alloys, Marcel Dekker Inc. New York, 253, 2001.

[29] Song G. L., Atrens A. Understanding magnesium corrosion. Advance Engineering Materials, 5, 837-858, 2003.

[30] Shreir L. L. Corrosion Tien Wah Press Ltd., Singapore. 1, 222, 197. 
